\title{
Utility of the Morisky Medication Adherence Scale in gout: a prospective study
}

This article was published in the following Dove Press journal:

Patient Preference and Adherence

2 December 2016

Number of times this article has been viewed

\section{CSL Tan' \\ GG Teng ${ }^{1,2}$ \\ KJ Chong ${ }^{2}$ \\ PP Cheung ${ }^{1,2}$ \\ AYN Lim ${ }^{1,2}$ \\ HL Wee ${ }^{3,4}$ \\ A Santosa ${ }^{1,2}$}

'University Medicine Cluster, Division of Rheumatology, National University Health System, ${ }^{2}$ Department of Medicine, Yong Loo Lin School of Medicine, ${ }^{3}$ Department of Pharmacy, Faculty of Science, ${ }^{4}$ Saw Swee Hock School of Public Health, National University of Singapore, Singapore
Correspondence: A Santosa University Medicine Cluster, Division of Rheumatology, National University Health System, Level 10 Tower Block, IE Lower Kent Ridge Road, Singapore I 1 9228, Singapore

Fax +65 6872 4I30

Email amelia_santosa@nuhs.edu.sg
Background: The outcomes of any chronic illness often depend on patients' adherence with their treatment. A tool is lacking to assess adherence in gout that is standardized, allows realtime feedback, and is easy to understand.

Objective: We set out to evaluate the utility of the 8-item Morisky Medication Adherence Scale (MMAS-8) in monitoring medication adherence in a multiethnic Asian gout cohort on urate-lowering therapy (ULT).

Methods: This cohort study recruited patients with gout where baseline and 6-monthly clinical data, self-report of adherence, and health status by Gout Impact Scale (GIS) and EuroQoL-5 dimension 3 levels were collected. Those who received at least 9 months of ULT were analyzed. Convergent and construct validities of MMAS- 8 were evaluated against medication possession ratio (MPR) and known groups, clinical outcomes, and patient-reported outcomes. Internal consistency and test-retest reliability were assessed using Cronbach's alpha and intraclass correlation coefficient (ICC), respectively.

Results: Of 91 patients, $92.3 \%$ were male, $72.5 \%$ Chinese with mean age 53.5 years. MMAS- 8 (mean 6.17) and MPR (mean 96.3\%) were poorly correlated ( $r=0.069, P=0.521$ ). MMAS-8 did not differ between those who did or did not achieve target serum urate (SU) $<360 \mu \mathrm{mol} / \mathrm{L}$ ( $P=0.852)$; or among those whose $\mathrm{SU}$ improved, stagnated, or worsened during follow-up $(P=0.777)$. Adherence was associated with age $(\beta=0.256, P=0.015)$ and education level $(P=0.011)$ but not comorbidities, polypharmacy, or flare frequency. Concerns for medication side effects and anxiety or depression were associated with lower MMAS-8 $(P<0.005)$. Internal consistency was acceptable $(\alpha=0.725)$ and test-retest reliability was satisfactory (ICC $=0.70,95 \%$ confidence interval [CI] 0.36-0.88).

Conclusion: MMAS- 8 had limited construct validity in assessing medication adherence to ULT in our gout patients. Nevertheless, it identified patients bothered or worried about ULT side effects, and those with underlying anxiety or depression, for whom targeted education and coping support may be useful.

Keywords: gout, 8-item Morisky Medication Adherence Scale, MMAS-8, serum urate, uratelowering therapy, Singapore

\section{Introduction}

Gout is a chronic disease caused by deposition of monosodium urate crystals around and within the joints, leading to inflammation, painful acute arthritis, and gradual joint destruction. ${ }^{1}$ Urate-lowering therapy (ULT) is necessary to lower and maintain serum urate (SU) levels at a therapeutic target of $<360 \mu \mathrm{mol} / \mathrm{L}$ as this is associated with fewer gout flares, reduction of tophus size, and depletion of urate crystal stores in synovial tissues. ${ }^{2-4}$

However, medication adherence to ULT is suboptimal. Adherence in gout was lowest at $36.8 \%$ among six common chronic diseases in a longitudinal study. ${ }^{5}$ In a recent 
systematic review, low rates of adherence $(17 \%$ - 44\%) were reported using electronic prescription records of patients with gout. ${ }^{6}$ Studies using other methods of adherence assessment including electronic medication packaging device trackers, pill count, clinician assessments, and patient self-reports consistently highlighted medication nonadherence in gout, ${ }^{6}$ which may in turn contribute to poor disease outcomes. ${ }^{7,8}$

The 8-item Morisky Medication Adherence Scale (MMAS-8) is a structured, self-reported 8-item questionnaire, ${ }^{9}$ which has been validated in several chronic diseases. ${ }^{10-13}$ As gout is mostly treated in the outpatient setting, we chose to use the MMAS- 8 because of its practicality, simplicity, feasibility for real-time feedback, and its acceptance by healthcare providers and patients. ${ }^{14}$ The aim of our study was to evaluate the use of MMAS-8 in a prospective cohort of patients with gout.

\section{Methods}

\section{Study population}

From 2011, adults aged $\geq 21$ years with gout fulfilling the 1977 American Rheumatism Association preliminary classification criteria of acute gout ${ }^{15}$ were prospectively recruited from the rheumatology clinics in a tertiary hospital. Patients who had been on ULT for at least 9 months by July 2014 (censor date) were included for analysis of adherence. Only patients who received allopurinol or probenecid as ULT were included. In Singapore, allopurinol and probenecid are the most commonly prescribed ULT. Patients on febuxostat, which was not yet licensed in Singapore at study commencement, or those taking nonstandard formulations such as benzbromarone were excluded because of potential inconsistent pharmacy supply. Written informed consent was obtained from all patients. The conduct of this study was approved by our Institutional Ethics Review Board, the National Healthcare Group Domain Specific Review Board.

\section{Clinical variables}

Patients recruited into the gout cohort were seen per routine clinical need with data capture at 6-monthly intervals. At baseline, sociodemographic data (age, gender, ethnicity, and education), lifestyle factors (cigarette smoking, alcohol, physical activity), gout characteristics (age of diagnosis, disease manifestations, past treatment), and comorbidities were obtained. Formal education was defined by completion of at least secondary school education. At each visit, flare status and severity, ongoing gout therapies (prophylaxis, ULT, and traditional Chinese medication), health-related quality of life (HRQoL) and physical functioning indices, and adherence data were collected. Clinical measurements such as the presence of tophus, gout flare status, and number of joints involved were determined through history and physical examination by a rheumatologist. Height, weight, and SU levels $(\mu \mathrm{mol} / \mathrm{L})$ were recorded at each review.

\section{HRQoL measures}

To assess HRQoL, we used the EuroQoL-5 dimension (EQ5D) three levels. ${ }^{16}$ The EQ5D is a simple 5-item tool with three levels of response options (no impairment, moderate impairment, and severe impairment) that provides a simple descriptive profile and a single index value for health status. ${ }^{17}$ In addition, patients also completed the disease-specific Gout Assessment Questionnaire (GAQ) version 2.0 at each study visit, which contains the Gout Impact Scale (GIS) ${ }^{18}$ and other sections describing the overall impact of their gout, frequency of attack, duration, and joint involvement. The 24-item GIS comprises five subscales representing the impact of gout overall ("Gout Concern Overall - 4 items", "Gout Medication Side Effects - 2 items", and "Unmet Gout Treatment Need - 3 items") and during an attack ("WellBeing During Attack - 11 items" and "Gout Concern During Attack - 4 items"). Each item in the GIS portion is rated on a 5-point Likert scale ("strongly agree" to "strongly disagree", "all of the time" to "none of the time", or "not a bit" to "extremely"). ${ }^{18}$ Subscales are scored from 0 to 100 , with higher scores on each subscale indicating "worse condition" or "greater gout impact". For this study, the subscales on "Gout Medication Side Effects" and "Unmet Gout Treatment Need" were of particular relevance as they reflect the patients' perception of their ULT. Questionnaires were in English and were self-administered by patients.

\section{Medication adherence measures}

Self-reported medication adherence was measured by the MMAS- $8 .{ }^{9}$ It consists of 8 items, with binary scoring for the first seven items and a 5-point Likert score for the last item. The last item contributes a score between zero and one in 0.25 -point increments on a 5-point scale assessing the frequency patients forget take medications (never $=1$, once in a while $=0.75$, sometimes $=0.5$, usually $=0.25$, and all the time $=0$ ). The total score is a summation of all MMAS- 8 items and ranges between 0 and 8 , with scores of 8 reflecting high adherence, 7 or 6 reflecting medium adherence, and $<6$ reflecting low adherence.

Medication possession ratio (MPR) is another measure of medication adherence. ${ }^{6}$ It is a ratio that summarizes the proportion of days a patient has a supply of medications for. 
The MPR can be presented as a fixed or variable measurement. The fixed MPR calculates medication possession rate over a fixed duration that is being studied. In comparison, variable MPR takes into account between-subject variation in treatment durations, depending on the exact dates of the subjects' prescriptions within a specified period that is being studied. Hence, the variable MPR can be viewed as a more precise measure of medication possession. ${ }^{19}$ The variable MPR is calculated through the following equation:

$$
\begin{gathered}
\text { Variable MPR }=\frac{\text { Days of dispensed medication }}{\text { (Days between last and first prescription }} \\
+ \text { Days of last prescription) }
\end{gathered}
$$

Perfect adherence is inferred when the ratio is $1(100 \%)$ and a cutoff of $\geq 80 \%$ has been determined to define adherence. As the MPR only assesses medication possession, it assumes that the patient consumes the medication obtained. Patients completed the MMAS-8 at each study visit and their MPRs were computed from retrospectively extracted pharmacy records for the corresponding time frame.

\section{Statistical analysis}

Baseline data such as gout characteristics, disease severity, treatment history, comorbidities, MMAS-8, MPR, EQ5D, and GIS were summarized descriptively. Categorical variables were reported as frequencies in percentages while continuous variables were reported in means and standard deviations using the independent Student's $t$-test (for two group comparisons) and the analysis of variance (for more than two group comparisons). The relationship between MMAS-8 and MPR was evaluated using Pearson's correlation. We expected the correlation between MMAS- 8 and MPR to be weak to moderate as shown in previous studies in other therapeutic areas. ${ }^{20-22}$

Construct validity of MMAS- 8 was assessed by comparing mean scores between known groups identified from published literature. We did the same for MPR and compared the two tools to determine which measure has better construct validity. We hypothesized that older patients, ${ }^{23}$ those with more comorbidities, ${ }^{5,24}$ higher education status, greater self-rated gout severity, and more frequent gout flares ${ }^{25}$ would have higher MMAS-8 scores (ie, higher adherence). We also postulated that patients with more concerns in the treatment-specific GIS subscales (namely the "Unmet gout treatment need" and "Gout medication side effects" scales) and those with anxiety or depression on EQ5D would have lower MMAS-8 scores (ie, lower adherence).
Criterion validity was assessed by examining the MMAS- 8 scores according to SU changes as an objective clinical outcome measure of gout. ${ }^{26}$ By assessing the change between baseline and final visits after at least 9 months of ULT, outcomes in SU level were categorized as follows: 1) improved (when SU decreased by $>50 \mu \mathrm{mol} / \mathrm{L}$ ); 2) worsened (when SU increased by $>50 \mu \mathrm{mol} / \mathrm{L}$ ); or 3 ) stayed the same (unchanged at $\pm 50 \mu \mathrm{mol} / \mathrm{L}$ from baseline). In addition, we defined remission as achievement of a target $\mathrm{SU}<360 \mu \mathrm{mol} / \mathrm{L}$ and absence of gout flares for 1 year. Similar analyses were performed for MPR scores.

Finally, test-retest reliability was assessed using the intraclass correlation coefficient (ICC) on 20 patients with retest in 2 weeks. Internal consistency was evaluated using the Cronbach's alpha with alpha $>0.70$ considered to be satisfactory. SPSS version 16.0 for Windows was used for the analyses.

\section{Results}

Between 2011 and 2014, 205 patients had been recruited into our gout cohort. After excluding patients who had been on ULT for $<9$ months and those on febuxostat and benzbromarone, 91 patients remained for analysis. Of these, $92.3 \%$ $(n=84)$ were men and $72.5 \%(n=66)$ were Chinese, with a mean age of 53.5 years (standard deviation, $\mathrm{SD}=16.0$ ) and mean body mass index of $29.7 \mathrm{~kg} / \mathrm{m}^{2}(\mathrm{SD}=7.7)$. The mean duration on ULT was 14.4 months $(\mathrm{SD}=2.9)$. Table 1 shows our cohort's demographic, lifestyle, and clinical characteristics at baseline.

Mean MMAS-8 was 6.17 (SD 1.8), of which 24.2\%, $37.7 \%$, and $37.8 \%$ of our subjects had high, medium, and low adherence, respectively. Mean MPR was 96.3\% (SD 18.9), and 83.5\% ( $\mathrm{n}=76)$ met the definition of adherence (ie, $\geq 80 \%$ ). A target $\mathrm{SU}<360 \mu \mathrm{mol} / \mathrm{L}$ was achieved by $57.1 \%$, but only $7.7 \%$ achieved our definition of remission during the study period.

The association between MMAS- 8 and known patient groups is depicted in Tables 2 and 3. Increasing age and lack of formal education were associated with higher MMAS-8 scores ( $P=0.015$ and $P=0.011$, respectively). Adherence was not influenced by number of comorbidities, polypharmacy, frequency of gout flares, the use of gout flare prophylaxis with either colchicine or prednisolone, or being on traditional Chinese medicine. Moderate to severe anxiety or depression on the basis of EQ5D was found in $15.5 \%$ of patients. These patients had lower MMAS- 8 scores compared to those with no anxiety or depression $(P=0.028)$. A significant proportion of patients reported in the GIS subscale 
Table I Demographic, lifestyle, and clinical characteristics of gout patients at baseline

\begin{tabular}{l} 
Variable \\
\hline Age, mean (years) \pm SD \\
Gender, $\mathrm{n}(\%)$ \\
Male \\
Race, $\mathrm{n}(\%)$ \\
Chinese \\
Malay \\
Indian \\
Body mass index (kg/m²), mean $\pm \mathrm{SD}$ \\
Formal education, $\mathrm{n}(\%)$ \\
Incomplete \\
Completed \\
Employment, $\mathrm{n}(\%)$ \\
Employed \\
Current alcohol consumption, $\mathrm{n}(\%)$ \\
Number of comorbidities, $\mathrm{n}(\%)$ \\
None \\
I \\
2
\end{tabular}

Baseline serum urate level $(\mu \mathrm{mol} / \mathrm{L})$, mean \pm SD

Tophaceous gout, $\mathrm{n}(\%)$

Crystal-proven gout, $\mathrm{n}(\%)$

Urate-lowering agents, $\mathrm{n}(\%)$

Allopurinol

Probenecid

Use of prophylaxis, $n$ (\%)

Colchicine

Prednisolone

Nonsteroidal anti-inflammatory drug

Number of gout attacks in past year, $n$ (\%)

$\leq 2$

3-5

$\geq 6$

Patient-rated gout severity, n (\%)

Mild

Moderate

Severe

Gout medication side effects, $\mathrm{n}(\%)^{*}$

Bothered by side effects from gout medications

(strongly agree and agree)

Worried about long-term effects of gout medications

(strongly agree and agree)

Unmet gout treatment needs, $\mathrm{n}(\%) *$

Current medications are effective for treating gout

attacks (strongly agree and agree)

Current medications do not work well to prevent

gout attacks (strongly agree and agree)

I have control over my gout (strongly agree and agree)

$\mathrm{EQ} 5 \mathrm{D}$, mean $\pm \mathrm{SD}$

EQ5D anxiety or depression, $n(\%)$

None

Moderate or extreme

$\mathbf{N}=9$ I

$53.5 \pm 16.9$

$84(92.3)$

$66(72.5)$

$24(26.4)$

I (I.I)

$29.7 \pm 7.7$

37 (40.7)

54 (59.3)

60 (65.9)

17 (18.7)

24 (26.4)

10 (11.0)

16 (17.6)

4I (45.I)

$613 \pm 118.4$

43 (47.3)

29 (31.9)

85 (93.4)

$6(6.6)$

32 (35.2)

12 (13.2)

I (I.I)

48 (52.7)

28 (30.8)

15 (16.5)

46 (50.6)

27 (29.7)

18 (19.8)

5 I (56.0)

$55(60.0)$

86 (94.5)

14 (15.4)

67 (73.6)

$0.9 \pm 0.2$

77 (83.5)

14 (15.5)

Note: *"Gout medication side effects" and "Unmet gout treatment needs" are subscales of the 24-item Gout Impact Scale, which contains treatment-specific items. Abbreviations: EQ5D, EuroQoL-5 dimension 3 levels; SD, standard deviation.
Table 2 Comparison of MMAS- 8 with known groups in gout

\begin{tabular}{|c|c|c|}
\hline Variable & $\begin{array}{l}\text { Mean MMAS-8 } \\
\text { score (SD) }\end{array}$ & $P$-value \\
\hline Gender & & 0.564 \\
\hline Male & $6.2(1.8)$ & \\
\hline Female & $5.8(2.5)$ & \\
\hline $\begin{array}{l}\text { Age at symptom onset (linear } \\
\text { regression; age at } 5 \text {-year intervals) }\end{array}$ & $\beta=0.256, S E=0.1 \mathrm{I}$ & 0.015 \\
\hline Race & & 0.590 \\
\hline Chinese & $6.1(1.9)$ & \\
\hline Malay & $6.2(1.7)$ & \\
\hline Formal education & & 0.011 \\
\hline Incomplete & $6.7(1.6)$ & \\
\hline Completed & $5.8(1.9)$ & \\
\hline Body mass index, ${ }^{*} \mathrm{~kg} / \mathrm{m}^{2}$ & & 0.225 \\
\hline $18.5-22.9(n=10)$ & $7.2(1.5)$ & \\
\hline $23-27.4(n=35)$ & $6.1(2.0)$ & \\
\hline$\geq 27.5(\mathrm{n}=46)$ & $6.0(1.8)$ & \\
\hline Comorbidities (linear regression) & $\beta=0.083, S E=0.10$ & 0.439 \\
\hline Tophaceous gout & & 0.567 \\
\hline Yes & $6.3(2.0)$ & \\
\hline No & $6.1(1.7)$ & \\
\hline Baseline serum urate level $(\mu \mathrm{mol} / \mathrm{L})$ & & 0.575 \\
\hline$<360$ & $6.1(1.9)$ & \\
\hline$\geq 360$ & $6.3(1.8)$ & \\
\hline Traditional Chinese medicine use & & 0.951 \\
\hline Yes $(n=6)$ & $6.1(2.4)$ & \\
\hline No $(n=85)$ & $6.2(0.2)$ & \\
\hline
\end{tabular}

Note: *Body mass index $\left(\mathrm{kg} / \mathrm{m}^{2}\right)$ - categorized according to those at low ( $\left.18.5-22.9\right)$, moderate (23-27.4), and high ( $\geq 27.5)$ risk for diabetes and cardiovascular diseases in Singaporean Asians. ${ }^{52}$

Abbreviations: MMAS-8, 8-item Morisky Medication Adherence Scale; SD, standard deviation; SE, standard error.

"Gout Medication Side Effects" that they had concerns about side effects $(50.0 \%)$ and long-term effects of gout medications $(60.0 \%)$. These items were associated with significantly lower MMAS-8 scores (Table 3).

Meanwhile, MPR scores were only influenced by the presence of tophi (Table S1). Hence, MMAS-8 exhibited better known group validity compared with MPR. There was no relationship between MMAS-8 and MPR ( $r=0.069$, $P=0.521)$. The mean MMAS- 8 was similar in those who achieved $\mathrm{SU}<360 \mu \mathrm{mol} / \mathrm{L}$ versus those who did not reach this target $\mathrm{SU}(P=0.852)$. Likewise, the mean MMAS-8 did not differ among the three SU outcome groups $(P=0.777)$; MMAS-8 and MPR scores did not differ between patients who did or did not achieve our definition of remission $(P=0.087)$.

Internal consistency of MMAS-8 was good (Cronbach's alpha $=0.73)$; its test-retest reliability $(n=18,20 \%$ sample $)$ was satisfactory (ICC 0.702 [95\% CI 0.362-0.877]). 
Table 3 Comparison of MMAS-8 with patient-reported outcomes

\begin{tabular}{|c|c|c|}
\hline Variable & $\begin{array}{l}\text { Mean MMAS } \\
\text { score (SD) }\end{array}$ & $P$-value \\
\hline Patient-rated gout severity & & 0.249 \\
\hline Mild & $6.4(1.5)$ & \\
\hline Moderate & $6.2(2.0)$ & \\
\hline Severe & $5.5(2.3)$ & \\
\hline Number of gout attacks in past year & & 0.786 \\
\hline$\leq 2$ & $6.3(1.6)$ & \\
\hline $3-5$ & $6.0(2.1)$ & \\
\hline$\geq 6$ & $6.0(2.2)$ & \\
\hline EQ5D, mean & $6.2(1.8)$ & 0.822 \\
\hline EQ5D anxiety or depression & & 0.028 \\
\hline None & $6.3(1.7)$ & \\
\hline Moderate or extreme & $5.2(2.0)$ & \\
\hline \multicolumn{3}{|l|}{ Gout medication side effects* } \\
\hline $\begin{array}{l}\text { Bothered by side effects of gout } \\
\text { medication }\end{array}$ & & $<0.001$ \\
\hline Yes & $5.5(1.8)$ & \\
\hline No & $7.1(1.6)$ & \\
\hline Worried about the long-term effects & & 0.004 \\
\hline of gout medications & & \\
\hline Yes & $5.7(1.7)$ & \\
\hline No & $7.0(1.8)$ & \\
\hline \multicolumn{3}{|l|}{ Unmet gout treatment needs* } \\
\hline $\begin{array}{l}\text { Current medications are effective for } \\
\text { treating a gout attack when I have one }\end{array}$ & & - \\
\hline Yes (only one observation) & $6.2(1.8)$ & \\
\hline No & $4.8(-)$ & \\
\hline $\begin{array}{l}\text { Current medications do not work well } \\
\text { to prevent gout attacks from happening }\end{array}$ & & 0.330 \\
\hline Yes & $5.7(2.1)$ & \\
\hline No & $6.3(1.8)$ & \\
\hline I have control over my gout & & 0.130 \\
\hline Yes & $6.3(1.7)$ & \\
\hline No & $4.3(2.7)$ & \\
\hline
\end{tabular}

Note: *"Gout medication side effects" and "Unmet gout treatment needs" are subscales of the 24-item Gout Impact Scale, which contains treatment-specific items. Abbreviations: EQ5D, EuroQoL-5 dimension 3 levels; MMAS-8, 8-item Morisky Medication Adherence Scale; SD, standard deviation.

\section{Discussion}

This is the first study to evaluate the use of MMAS- 8 in assessing medication adherence to ULT in the management of gout in an Asian cohort. The majority (61.9\%) of our gout patients had good (medium to high) adherence to ULT on MMAS-8, compatible with the adherence described in other chronic diseases ${ }^{27-29}$ using the same tool. As expected from a self-report measure, adherence in our gout cohort appears to be high, similar to another study of adherence to ULT, where adherence was assessed through the Medication Adherence Report Scale. ${ }^{25}$

Previous studies have found that adherence to gout medications is associated with higher baseline gout severity, but predicted better gout outcomes, such as control of flares and achieving target SU level. ${ }^{30,31}$ However, in our cohort, MMAS-8 was not influenced by known markers of gout severity such as baseline SU level, patient-reported gout severity, and presence of tophi, and therefore appeared to have limited value for measuring adherence in our local patients with gout. One possible explanation is the discrepancy between physician- and patient-perceived disease severity. While physicians perceive objective factors, in particular the presence of tophi or high SU levels, as determinants of disease severity, these may not directly impact the patients' quality of life. Hence, they may not influence their adherence to treatment. ${ }^{32}$ Other clinical markers of disease severity that we had expected to impact a patient's quality of life, such as patient self-rated severity and frequency of flares in the past year, similarly seemed to have no influence on MMAS-8 scores. We expected adherence to be associated with fewer flares, ${ }^{31}$ by virtue of SU level reduction while on regular ULT. Instead, we observed a trend for more frequent flares in adherent patients. This may be accounted for by the relatively short follow-up (mean duration on ULT of 14.4 months). During this period only approximately half of our patients reached target SU while the rest were still on dose titration. It is well recognized that patients may experience more flares during the initial period of ULT titration, and, therefore, prophylaxis is recommended during the first 6 months. ${ }^{33}$ Unfortunately, less than half of our patients were on prophylaxis with either colchicine or nonsteroidal antiinflammatory drugs, complicating the interpretation of the higher flare rate among adherent patients.

The influence of adherence on achievement of target SU levels is debatable. While some studies demonstrated that better adherence is associated with achievement of target SU or reduction in SU levels, the findings have been inconsistent. ${ }^{25,30,34}$ In a recent cross-sectional study of gout patients on ULT, adherence was not independently associated with SU target. Other health-related perceptions such as confidence with therapy and disease understanding did not influence SU level either. Instead, the dose at which the ULT is prescribed, that is, how diligently ULT dose titration was pursued, determined achievement of SU target in that study. ${ }^{35}$ While we did not analyze ULT dosing patterns in our cohort, closer analysis of the individual prescriptions could help to identify additional areas for improvement in the management of patients with gout.

Other groups have shown that older age was associated with better compliance in gout ${ }^{23,36,37}$ and other diseases, ${ }^{38}$ 
potentially because of older patients' experience in managing chronic diseases ${ }^{36}$ and willingness to be committed to lifelong medication. Likewise, an increased number of comorbid illnesses were shown to be associated with increased adherence to gout medications. ${ }^{5,24}$ It is postulated that comorbid illnesses that may be perceived as being more life threatening changed a patient's overall attitude toward medication consumption. ${ }^{24}$ In our cohort, there was no association between adherence and the number of comorbidities. Interestingly, we found that patients with formal education were less adherent. This phenomenon has been reported in lupus ${ }^{39,40}$ and psychiatric patients. ${ }^{41}$ It is postulated that educated patients are more critical of their doctors' advice and often have their own perceptions of how their disease should be treated, be it correct or misguided, depending on their source of information. ${ }^{42-44}$

Our study revealed that MMAS- 8 is able to elucidate certain concerns about medications. For instance, being bothered by and worried about medication side effects were predictably associated with lower MMAS-8 scores, while unmet treatment needs did not influence MMAS-8. Several qualitative studies in gout also demonstrated that patients' experience or concern for side effects is often a contributor to lower adherence to their gout treatment regimen. ${ }^{25,45,46}$ MMAS-8 was able to identify patients with moderate to severe anxiety or depression and therefore those who may be apprehensive about ULT. Gout patients who had difficulty with coping, poorer overall health status, and greater emotional response to their disease (ie, being more emotionally affected by the gout) had been shown to have reduced adherence to treatment. ${ }^{25,47}$ This study draws our attention to a group of patients who would benefit from more careful assessment of compliance. They are the younger patients, those who display anxious or depressive traits, and those who have highlighted concerns of ULT. It will be worthwhile to then enquire about their beliefs about medications and address them through dedicated disease- and medicationspecific education. An individualized treatment plan $^{48}$ may need to be devised for each patient, depending on specific concerns. Patients may also benefit from additional support to cope with their disease.

We noted an absence of association between MMAS-8 and MPR. MPR categorized a higher proportion of patients as adherent $(83.5 \%$ vs $61.9 \%$ patients with medium-high adherence on MMAS) and our cohort's mean MPR was very high (96.3\%) compared with other studies where MPRs ranged between $54 \%$ and $75 \% .{ }^{6}$ However, as MPR is a measure of medication possession, it does not reflect actual medication consumption and may thus overestimate our cohort's actual compliance to ULT. High MPRs seem to be a consistent observation in our country, as demonstrated in other local studies of patients with diabetes ${ }^{49}$ and osteoporosis. ${ }^{50} \mathrm{In}$ Singapore, the convenience of on-site pharmacies within hospitals and clinics may account for the higher likelihood of prescriptions being filled after each doctor's visit. In addition, we speculate that societal culture of politely accepting highly subsidized medications plays a role. This calls into question the utility of MPR in our local context.

The strength of our study was that it was a prospective study, consisting of patients under the care of rheumatologists and accurate gout diagnosis, out of which the majority had objective evidence of gout ( $47.3 \%$ had tophi and $31.9 \%$ had presence of crystals in synovial fluid). We had comprehensive pharmacy data for accurate calculation of MPR. Although the sample size was small and patients were recruited from specialized clinics in a tertiary care setting, there was a wide spectrum of disease severity and characteristics including those with gout as sole diagnosis. Thus, the results may still be readily generalizable to those who are on ULT in the primary care setting. Self-reported adherence questionnaires are prone to biases from wrong data input by patients, nonstandardized conduct of the interviews, and the patient's psychological state.$^{51}$ However, our participants in doubt had the benefit of referring to a research assistant to ensure understanding and accurate data entry.

A limitation of our study is that we did not use an electronic medication monitoring device. Nonetheless, this method is not perfect because opening the bottle does not equate to consuming the medications. Our relatively short follow-up means that a significant proportion of patients were still undergoing ULT titration at the final visit. It is likely that SU levels fluctuate during this period, and certain outcomes, such as cessation of flares, would only be reached later. Longer follow-up would allow most patients to reach a stable plateau, allowing us to assess the eventual influence of adherence on flares and SU level. However, adherence to treatment from the onset of therapy determines eventual disease outcome, and early identification of potential patient concerns would allow timely counselling and adjustment of therapy, if indicated. Consistent physician prescription of prophylactic medications for all patients newly commenced on ULT may have helped to eliminate confounding by flares inherent to initial ULT titration.

\section{Conclusion}

While MMAS-8 displayed satisfactory internal consistency and test-retest reliability, it was not associated with clinically 
objective outcome measures of gout in this local study. However, it distinguished patients with poor adherence because of experience of or worries about medication side effects, anxiety, and depression, and may be used to identify this subgroup of patients who may benefit from targeted patient education and coping support.

\section{Acknowledgments}

MMAS-8 license fee was supported by Dr Gim Gee Teng's Indirect Research Cost account (NDRF3020070I), which is a cumulative general purpose fund that holds the Principal Investigator's share of the Indirect Research Cost levied on grantors. Use of this fund is subject to institution guidelines on payable items.

We acknowledge the kind permission obtained from Takeda Pharmaceuticals in May 2009 to use the GAQ 2.0 in Singapore. Registration of research for use of EuroQoL-5 dimension 3 levels (EQ5D) was obtained on 10 September 2014.

\section{Disclosure}

The authors report no conflicts of interest in this work.

\section{References}

1. Choi HK, Curhan G. Gout: epidemiology and lifestyle choices. Curr Opin Rheumatol. 2005;17(3):341-345.

2. Mikuls TR, MacLean CH, Olivieri J, et al. Quality of care indicators for gout management. Arthritis Rheum. 2004;50(3):937-943.

3. Perez-Ruiz F, Liote F. Lowering serum uric acid levels: what is the optimal target for improving clinical outcomes in gout? Arthritis Rheum. 2007;57(7):1324-1328.

4. Zhang W, Doherty M, Bardin T, et al. EULAR evidence based recommendations for gout. Part II: Management. Report of a task force of the EULAR Standing Committee for International Clinical Studies Including Therapeutics (ESCISIT). Ann Rheum Dis. 2006;65(10):1312-1324.

5. Briesacher BA, Andrade SE, Fouayzi H, Chan KA. Comparison of drug adherence rates among patients with seven different medical conditions. Pharmacotherapy. 2008;28(4):437-443.

6. De Vera MA, Marcotte G, Rai S, Galo JS, Bhole V. Medication adherence in gout: a systematic review. Arthritis Care Res (Hoboken). 2014; 66(10):1551-1559.

7. Halpern R, Mody RR, Fuldeore MJ, Patel PA, Mikuls TR. Impact of noncompliance with urate-lowering drug on serum urate and goutrelated healthcare costs: administrative claims analysis. Curr Med Res Opin. 2009;25(7):1711-1719.

8. Rashid N, Coburn BW, Wu YL, et al. Modifiable factors associated with allopurinol adherence and outcomes among patients with gout in an integrated healthcare system. J Rheumatol. 2015;42(3):504-512.

9. Morisky DE, Ang A, Krousel-Wood M, Ward HJ. Predictive validity of a medication adherence measure in an outpatient setting. $J$ Clin Hypertens (Greenwich). 2008;10(5):348-354.

10. de Oliveira-Filho AD, Morisky DE, Neves SJ, Costa FA, de Lyra DP Jr. The 8-item Morisky Medication Adherence Scale: validation of a Brazilian-Portuguese version in hypertensive adults. Res Social Adm Pharm. 2014;10(3):554-561.

11. Moharamzad Y, Saadat H, Nakhjavan Shahraki B, et al. Validation of the Persian version of the 8-Item Morisky Medication Adherence Scale (MMAS-8) in Iranian hypertensive patients. Glob J Health Sci. 2015;7(4):173-183.
12. Ashur ST, Shamsuddin K, Shah SA, Bosseri S, Morisky DE. Reliability and known-group validity of the Arabic version of the 8-item Morisky Medication Adherence Scale among type 2 diabetes mellitus patients. East Mediterr Health J. 2015;21(10):722-728.

13. Yang A, Wang B, Zhu G, et al. Validation of Chinese version of the Morisky medication adherence scale in patients with epilepsy. Seizure. 2014;23(4):295-299.

14. Lam WY, Fresco P. Medication adherence measures: an overview. Biomed Res Int. 2015;2015:217047.

15. Wallace SL, Robinson H, Masi AT, Decker JL, McCarty DJ, Yu TF. Preliminary criteria for the classification of the acute arthritis of primary gout. Arthritis Rheum. 1977;20(3):895-900.

16. Herdman M, Gudex C, Lloyd A, et al. Development and preliminary testing of the new five-level version of EQ-5D (EQ-5D-5L). Qual Life Res. 2011;20(10):1727-1736.

17. Rabin R, de Charro F. EQ-5D: a measure of health status from the EuroQol Group. Ann Med. 2001;33(5):337-343.

18. Hirsch JD, Lee SJ, Terkeltaub R, et al. Evaluation of an instrument assessing influence of Gout on health-related quality of life. $J$ Rheumatol. 2008;35(12):2406-2414.

19. Kozma CM, Dickson M, Phillips AL, Meletiche DM. Medication possession ratio: implications of using fixed and variable observation periods in assessing adherence with disease-modifying drugs in patients with multiple sclerosis. Patient Prefer Adherence. 2013;7:509-516.

20. Font R, Espinas JA, Gil-Gil M, et al. Prescription refill, patient selfreport and physician report in assessing adherence to oral endocrine therapy in early breast cancer patients: a retrospective cohort study in Catalonia, Spain. Br J Cancer. 2012;107(8):1249-1256.

21. Koneru S, Shishov M, Ware A, et al. Effectively measuring adherence to medications for systemic lupus erythematosus in a clinical setting. Arthritis Rheum. 2007;57(6):1000-1006.

22. Pasma A, den Boer E, van't Spijker A, et al. Nonadherence to disease modifying antirheumatic drugs in the first year after diagnosis: comparing three adherence measures in early arthritis patients. Rheumatology. 2016;55(10):1812-1819.

23. Riedel AA, Nelson M, Joseph-Ridge N, Wallace K, MacDonald P, Becker M. Compliance with allopurinol therapy among managed care enrollees with gout: a retrospective analysis of administrative claims. J Rheumatol. 2004;31(8):1575-1581.

24. Zandman-Goddard G, Amital H, Shamrayevsky N, Raz R, Shalev V, Chodick G. Rates of adherence and persistence with allopurinol therapy among gout patients in Israel. Rheumatology (Oxford). 2013;52(6): 1126-1131.

25. Dalbeth N, Petrie KJ, House M, et al. Illness perceptions in patients with gout and the relationship with progression of musculoskeletal disability. Arthritis Care Res (Hoboken). 2011;63(11):1605-1612.

26. Taylor WJ, Schumacher HR Jr, Baraf HS, et al. A modified Delphi exercise to determine the extent of consensus with OMERACT outcome domains for studies of acute and chronic gout. Ann Rheum Dis. 2008; 67(6):888-891.

27. Oguzulgen IK, Kokturk N, Isikdogan Z. [Turkish validation study of Morisky 8-item medication adherence questionnaire (MMAS-8) in patients with asthma and chronic obstructive pulmonary disease]. Tuberk Toraks. 2014;62(2):101-107. Indonesian.

28. Wong $\mathrm{MC}, \mathrm{Wu} \mathrm{CH}$, Wang $\mathrm{HH}$, et al. Association between the 8-item Morisky medication adherence scale (MMAS-8) score and glycaemic control among Chinese diabetes patients. J Clin Pharmacol. 2015; 55(3):279-287.

29. Saarti S, Hajj A, Karam L, et al. Association between adherence, treatment satisfaction and illness perception in hypertensive patients. $J$ Hum Hypertens. 2016;30(5):341-345.

30. Park H, Rascati KL, Prasla K, McBayne T. Evaluation of health care costs and utilization patterns for patients with gout. Clin Ther. 2012;34(3): 640-652.

31. Sarawate CA, Brewer KK, Yang W, et al. Gout medication treatment patterns and adherence to standards of care from a managed care perspective. Mayo Clin Proc. 2006;81(7):925-934. 
32. Sarkin AJ, Levack AE, Shieh MM, et al. Predictors of doctor-rated and patient-rated gout severity: gout impact scales improve assessment. J Eval Clin Pract. 2010;16(6):1244-1247.

33. Richette P, Doherty M, Pascual E, et al. 2016 updated EULAR evidencebased recommendations for the management of gout. Ann Rheum Dis. Epub 2016 Jul 25.

34. Singh JA, Hodges JS, Asch SM. Opportunities for improving medication use and monitoring in gout. Ann Rheum Dis. 2009;68(8):1265-1270.

35. Dalbeth N, House ME, Horne A, Petrie KJ, McQueen FM, Taylor WJ. Prescription and dosing of urate-lowering therapy, rather than patient behaviours, are the key modifiable factors associated with targeting serum urate in gout. BMC Musculoskelet Disord. 2012;13:174.

36. Harrold LR, Andrade SE, Briesacher BA, et al. Adherence with uratelowering therapies for the treatment of gout. Arthritis Res Ther. 2009; 11(2):R46.

37. Solomon DH, Avorn J, Levin R, Brookhart MA. Uric acid lowering therapy: prescribing patterns in a large cohort of older adults. Ann Rheum Dis. 2008;67(5):609-613.

38. Lee R, Taira DA. Adherence to oral hypoglycemic agents in Hawaii. Prev Chronic Dis. 2005;2(2):A09.

39. Gross R, Graybill J, Wahezi D, Jordan NC, Putterman C, Blanco I. Increased education is associated with decreased compliance in an urban multi-ethnic lupus cohort. J Clin Cell Immunol. 2014;5(3):215.

40. Nived O, Andersson M, Lindgren M, et al. Adherence with advice and prescriptions in SLE is mostly good, but better follow up is needed: a study with a questionnaire. Lupus. 2007;16(9):701-706.

41. Ruscher SM, de Wit R, Mazmanian D. Psychiatric patients' attitudes about medication and factors affecting noncompliance. Psychiatr Serv. 1997;48(1):82-85.

42. Kowalczyk N, Draper LJ. Trends in patient information preferences and acquisition. Radiol Technol. 2012;83(4):316-324.
43. Hay MC, Cadigan RJ, Khanna D, et al. Prepared patients: internet information seeking by new rheumatology patients. Arthritis Rheum. 2008; 59(4):575-582.

44. Suarez-Almazor ME, Kendall CJ, Dorgan M. Surfing the Net information on the World Wide Web for persons with arthritis: patient empowerment or patient deceit? J Rheumatol. 2001;28(1):185-191.

45. Singh JA. Facilitators and barriers to adherence to urate-lowering therapy in African-Americans with gout: a qualitative study. Arthritis Res Ther. 2014;16(2):R82.

46. Spencer K, Carr A, Doherty M. Patient and provider barriers to effective management of gout in general practice: a qualitative study. Ann Rheum Dis. 2012;71(9):1490-1495.

47. de Klerk E, van der Heijde D, Landewe R, van der Tempel H, Urquhart J, van der Linden S. Patient compliance in rheumatoid arthritis, polymyalgia rheumatica, and gout. $J$ Rheumatol. 2003;30(1):44-54.

48. Rees F, Jenkins W, Doherty M. Patients with gout adhere to curative treatment if informed appropriately: proof-of-concept observational study. Ann Rheum Dis. 2013;72(6):826-830.

49. Cheen HH, Lim SH, Huang MC, Bee YM, Wee HL. Adherence to premixed insulin in a prefilled pen compared with a vial/syringe in people with diabetes in Singapore. Clin Ther. 2014;36(7):1043-1053.

50. Cheen MH, Kong MC, Zhang RF, Tee FM, Chandran M. Adherence to osteoporosis medications amongst Singaporean patients. Osteoporos Int. 2012;23(3):1053-1060.

51. Svarstad BL, Chewning BA, Sleath BL, Claesson C. The Brief Medication Questionnaire: a tool for screening patient adherence and barriers to adherence. Patient Educ Couns. 1999;37(2):113-124.

52. Goh LG, Jonathan P. Obesity in Singapore, prevention and control. Singapore Fam Physician. 2012;38(1):8-13. 


\section{Supplementary material}

Table SI Medication possession ratio against known groups in gout

\begin{tabular}{|c|c|c|}
\hline Variable & $\begin{array}{l}\text { Mean medication possession } \\
\text { ratio (standard deviation) }\end{array}$ & $P$-value \\
\hline Gender & & 0.054 \\
\hline Male & $97(18)$ & \\
\hline Female & $83(26)$ & \\
\hline $\begin{array}{l}\text { Age at symptom onset (linear } \\
\text { regression done every } 5 \text { years) }\end{array}$ & $\beta=-0.065, \mathrm{SE}=0.12 \mathrm{I}$ & 0.542 \\
\hline Race & & 0.997 \\
\hline Chinese & $96(20)$ & \\
\hline Malay & $96(17)$ & \\
\hline Formal education & & 0.256 \\
\hline Incomplete & $99(18)$ & \\
\hline Completed & $94(19)$ & \\
\hline Body mass index in $\mathrm{kg} / \mathrm{m}^{2}, *$ & & 0.711 \\
\hline $18.5-22.9(n=10)$ & $100(12)$ & \\
\hline $23-27.4(n=35)$ & $97(2 \mathrm{I})$ & \\
\hline$\geq 27.5(\mathrm{n}=46)$ & $96(17)$ & \\
\hline Comorbidities (linear regression) & $\beta=0.04 \mathrm{I}, \mathrm{SE}=1.05$ & 0.698 \\
\hline Tophaceous gout & & 0.003 \\
\hline Yes & $100(15)$ & \\
\hline No & $91(20)$ & \\
\hline Baseline serum urate level $(\mu \mathrm{mol} / \mathrm{L})$ & & 0.840 \\
\hline$<360$ & $97(20)$ & \\
\hline$\geq 360$ & $96(19)$ & \\
\hline Traditional Chinese medicine use & & 0.956 \\
\hline Yes $(n=6)$ & $97(20)$ & \\
\hline No $(n=85)$ & $96(19)$ & \\
\hline
\end{tabular}

Notes: *Body mass index $\left(\mathrm{kg} / \mathrm{m}^{2}\right)$ - categorized according to those at low (I8.5-22.9), moderate (23-27.4), and high ( $\left.\geq 27.5\right)$ risk for diabetes and cardiovascular diseases in Singaporean Asians.'

Abbreviation: SE, standard error.

\section{Reference}

1. Goh LG, Jonathan P. Obesity in Singapore, prevention and control. Singapore Fam Physician. 2012;38(1):8-13.

\section{Publish your work in this journal}

Patient Preference and Adherence is an international, peer-reviewed, open access journal that focuses on the growing importance of patient preference and adherence throughout the therapeutic continuum. Patient satisfaction, acceptability, quality of life, compliance, persistence and their role in developing new therapeutic modalities and compounds to optimize

\section{Dovepress}

clinical outcomes for existing disease states are major areas of interest for the journal. This journal has been accepted for indexing on PubMed Central. The manuscript management system is completely online and includes a very quick and fair peer-review system, which is all easy to use. Visit http://www. dovepress.com/testimonials.php to read real quotes from published authors.

\footnotetext{
Submit your manuscript here: http://www.dovepress.com/patient-preference-and-adherence-journal
} 